\title{
Formation of Language Competence: Modern Issues and Strategies in the Area of Cross-Cultural Communication
}

Larisa Anatolyevna Kosareva, ${ }^{+*}$ Olga Anatolyevna Evreeva, ${ }^{\neq}$and Oksana Vyacheslavovna Zakirova ${ }^{\uparrow}$

\section{Abstract}

In the framework of globalisation, the development of cross-cultural communication skills is of high interest. However, there is no due attention paid to the development of intercultural language competence in all universities as well as the possibility to share it directly with native interlocutors of the other culture. The objective of the article is to define the critical complexities in the area of cross-cultural communication among those who study a foreign language. Another objective is to elaborate recommendations that will enable the solution of the issues in the area of cross-cultural communication within up-to-date education. As a result, the researchers' have organised and carried out the survey among 650 linguistic students of the 4th course from four largest Russian higher educational institutions (Peoples' Friendship University of Russia, Higher School of Economics, Moscow State Institute of International Relations, and Moscow State University). The outcomes of the research can be used in future as the basis for the development of cross-cultural communication for university students, which should have cross-cultural competence.

Keywords: Cross-Cultural Communication; Language Competence; Higher Education Institutions; CrossCultural Competence

\footnotetext{
${ }^{\dagger}$ People's Friendship University of Russia (RUDN University), Russian Federation

*Corresponding Author, Email: lara.kosareva.71@bk.ru

${ }^{\sharp}$ Russian State Social University, Russian Federation, Email: alla.evtyugina@bk.ru

îKazan Federal University, Russian Federation, Email: kuzgibekovaa@yahoo.com

(C) 2019 Kosareva et al.This is an Open Access article distributed under the terms of the Creative Commons Attribution License (http://creativecommons.org/licenses/by/2.0), which permits unrestricted use, distribution, and reproduction in any medium, provided the original work is properly cited.
} 


\section{Introduction}

Due to increased global mobility and available technologies that make cross-cultural communication easier on various continents, researches in the area of cross-cultural communication today are more relevant rather than before (Barrett, 2013). Education forms, which aim to develop cross-cultural communication skills, are increasingly common in all kinds of contemporary institutions, ranging from elementary schools to multinational corporations (Cameron, 2002; Xu, 2013). Skills in the area of cross-cultural communication comprise the ability to cooperate with the native bearers of the culture of the host country (Chen, 2011; Barker, 2016). If the goal of studying a language is the usage of the language, then the development of language usage skill should be defined and assessed by the capability of communication. In naturalistic (non-classroom) settings, human language communication, of course, takes both oral and written forms and develops in one or more languages wherever social interaction occurs (Savignon, 2017).

The latest model of communication competence keeps the leading position of social and cultural communication (Safina, 2014; Lantz-Deaton, 2017). The latter means pragmatic knowledge of the speaker, namely how in a due manner to express oneself in an entire social and cultural context of the talk. It contains the knowledge of language variation referring to social and cultural standards of the target language (Baraldi, 2006; Celce-Murcia, 2008). In fact, social and cultural mistake can be much more serious compared to the language mistake when somebody participates in oral communication (Oliver et al., 2005). Completeness, consistency and transparency as well as adequacy are of great importance in awareness and teaching cross-cultural communication competence (Piller, 2017). It is necessary to monitor whether all aspects of cross-cultural communication competence have been taken into account (completeness), that their connection to the training becomes evident (consistency) and that they can be understood by all participants of the talk (Spencer-Rodgers \& McGovern, 2002).

One of the difficulties of intercultural communication is the translation of terms and ethnographic concepts, where the most common translation tools are transliteration and equivalent translation (Mukhtarova et al., 2019). However, loan translation and neologisms may also occur during translation, which reduces the quality of intercultural communication. Hence, the inclusion of translation techniques in language learning strategies becomes mandatory (Lee, 2010). The quality of students' intercultural competence depends on the quality of language competence. Since each language contains a number of language units that serve as the key to understanding the culture of its native speakers (Akizhanova et al., 2018). Through the national-cultural marking of a linguistic attribute, participants of intercultural communication can understand the nationalcultural values of the interlocutor (Kiynova et al., 2018). The latter will contribute to the psychological adaptation of participants: their psychological well-being and sociocultural competence (Sam \& Berry, 2010).

Thus, the complex process of of mastering the competence of intercultural communication should take into account:

- The most effective strategies for learning a foreign language.

- The terminology and classification of foreign cultures.

- The use of new educational technologies and models.

- The influence of the cultural context when choosing a language for learning (Chamot, 2004).

Taking these backdrops into consideration, the key objectives of the research are:

- To examine how the level of language competence influences the development of cross-cultural communication competence skills. 
- Defining key complex issues in the area of cross-cultural communication among students of the foreign language course.

- Making up recommendations which can help to solve the issues within the crosscultural communication in contemporary education.

The paper consists of seven main sections. The rationale of the research has already been discussed in the introduction describing the problematic issues in the area of cross-cultural communication within up-to-date education. The following section reviews key literature relevant to the research demonstrating the central aspects of the problems of students' mastery of cross-cultural competence presented in relevant studies of international linguists. The section following thispresents the research sample, study design, participant's selection criterion, used questionnaires, the grounds of statistical analysis and possible research limitations. The results section describes the data obtained after the experiment. The researchers propose ways to improve students' language competences and professors' readiness to work in a multicultural environment. Discussion part reveals the international perspective of the research issue using the comparative approach. In conclusions, the summary of the study is presented.

\section{Literature Review}

If students live in an environment where they do not have direct face-to-face contact with native speakers, their needs will differ from those who have a constant face-to-face contact with native speakers. Specified needs of certain students can differ from the general level of intercultural contacts in the society in the form that it exists today (Gudykunst et al., 2005). As certain students are developing differently it is necessary to bear it in mind while teaching and training (Block \& Cameron, 2002). The objectives in the elaboration of the curriculum and teaching materials on a foreign language should not be in conflict. Communication competence should always comprise cultural competence (SpencerRodgers \& McGovern, 2002).
A special place in the process of mastering crosscultural competence is occupied by proper names, which are the result of cultural and linguistic interaction (Novikova et al., 2019). At the same time, the professor gives the base for the use of proper names for students, demonstrating the most relevant speech turns in communication with them. Thus, the professor's level of preparation, through an example of which students will form intercultural language competence, becomes highly essential (Fahrutdinova et al., 2014). Besides, through the professor, the student masters cultural keywords - a number of language units that serve as the key to understanding the culture of native speakers. Such language units directly serve as a tool for cross-cultural communication and as indicators for describing and understanding cultures (Akizhanova et al., 2018).

Mastering cross-cultural competence ensures the construction of a single ethnic identity of an international student and a native speaker in the communication process, thereby maximum communication efficiency is achieved and the risk of inter-ethnic conflict, due to misunderstanding, is minimised (Tsapko et al., 2018). The next section discusses the issues linked to methodology.

\section{Methods}

\section{Participants}

Based on the identified objectives, empirical research was organised and carried out which consisted of the survey of students at the bachelor's level from four state institutions of higher education. In total 650 students aged 20 to 21 ( $68 \%$ women and $32 \%$ men) participated in the survey (Table 1). All participants were the students of full-time education. The purposive sampling was considered as the most suitable way of the sampling. Prior to the collection of the data the consultation with the experts was held with the purpose of the soundness of the questionnaire. The experts from communication and language units assessed the questionnaire as an appropriate tool for the present research. 


\begin{tabular}{|c|c|c|c|}
\hline Number of the Students & Age & University & Special Field \\
\hline 177 & $20-21$ & $\begin{array}{l}\text { Peoples' Friendship } \\
\text { University of Russia }\end{array}$ & Linguistics \\
\hline 198 & $20-21$ & $\begin{array}{l}\text { Higher School of } \\
\text { Economics }\end{array}$ & $\begin{array}{c}\text { Foreign languages and } \\
\text { cross-cultural } \\
\text { communication }\end{array}$ \\
\hline 125 & $20-21$ & $\begin{array}{c}\text { Moscow } \\
\text { State Institute of } \\
\text { International Relations }\end{array}$ & $\begin{array}{l}\text { Translation, linguistic } \\
\text { and cultural studies, } \\
\text { and cross-cultural } \\
\text { communication }\end{array}$ \\
\hline 150 & $20-21$ & Moscow State University & $\begin{array}{c}\text { Faculty of foreign } \\
\text { languages and regional } \\
\text { studies }\end{array}$ \\
\hline
\end{tabular}

\section{The Participant's Selection Criterion}

The survey was held among students of the fourth course. The selection of such an audience of learners is stipulated by the fact that students of senior course are deemed to be potentially more qualified working human resources. Besides, at this stage of the study, the students have already passed most part of special courses of their field, performed practical tasks as well as completed internship. They have sophisticated experience in studying foreign languages and cross-cultural communication.

\section{Research Design}

The students' survey was carried out in two stages and consisted of two questionnaires (see Tables 2 and 3).

\section{Research Restrictions}

The survey data were collected by ten linguistic professors by interviewing their students for two months in the class. Since the answers and the involvement of students in the survey could be determined by the relationship between the professor and students, this could affect the quality of the respondents' answers. Another limitation of the study could be the ethical problem of following uniform standards while interviewing students from ethnic minorities who study alongside with the Russian students in the same study groups. Such students are native speakers of a non-Russian language, and the Russian culture is to some extent foreign to them. Thus, their answers do not fully reflect the problems, as they are already in the permanent process of acculturation and development of intercultural communication skills.

In the research, only students of fourth year have participated. All of them have studied at the faculties related to linguistics. Furthermore, the research has been held particularly in higher education institutions of the Russian Federation that enables identification of the issue on a larger scale.

Further research may be carried out in larger scale: among junior and senior students with the purpose to compare the dynamics, and among students of Master programmes in order to heighten awareness of the issue and obtain more general assumptions. Besides, similar researches may be conducted at other faculties where the aspect of intercultural cooperation is of concern (for example, at the faculties of international affairs). 


\section{Table 2: Questionnaire: Cross-Cultural Communication}

\begin{tabular}{|c|c|}
\hline Questions & Options of answer \\
\hline $\begin{array}{l}\text { 1. Do you know the meaning of } \\
\text { "communication competence"? }\end{array}$ & Yes, no, difficult to answer. \\
\hline $\begin{array}{l}\text { 2. Do you know the meaning of "cross-cultural } \\
\text { communication"? }\end{array}$ & Yes, no, difficult to answer. \\
\hline $\begin{array}{l}\text { 3. Do you understand the difference between } \\
\text { communication competence and cross- } \\
\text { cultural communication? }\end{array}$ & Yes, no, difficult to answer. \\
\hline $\begin{array}{l}\text { 4. Do you think that without proper cross- } \\
\text { cultural competence it is impossible to have } \\
\text { entire cooperation with the representative of } \\
\text { other culture? }\end{array}$ & Yes, no, difficult to answer. \\
\hline $\begin{array}{l}\text { 5. Is it important to have knowledge of cross- } \\
\text { cultural communication upon studying a } \\
\text { foreign language? }\end{array}$ & Important, unimportant, difficult to answer. \\
\hline $\begin{array}{l}\text { 6. Do you think whether the information } \\
\text { about countries of studied languages } \\
\text { stipulated in school manuals and instructions } \\
\text { of higher education institutions is enough? }\end{array}$ & Yes, no, not always. \\
\hline $\begin{array}{l}\text { 7. Does your education institution provide } \\
\text { additional information referred to the culture } \\
\text { of the countries of the studied languages? }\end{array}$ & Yes (write down what institution), no. \\
\hline $\begin{array}{l}\text { 8. Does the methodology of your professors } \\
\text { improve your awareness in the area of cross- } \\
\text { cultural communication? }\end{array}$ & Yes, no, difficult to answer. \\
\hline $\begin{array}{l}\text { 9. Do you think that it is impossible to reach } \\
\text { the appropriate level of cross-cultural } \\
\text { competence only in the higher education } \\
\text { institutions (that is, it is necessary to } \\
\text { communicate with international students, } \\
\text { travelling, etc.)? }\end{array}$ & Yes, no, difficult to answer. \\
\hline $\begin{array}{l}\text { 10. Is there online forum in your university on } \\
\text { foreign languages which allows } \\
\text { communicating with other students as well as } \\
\text { with international students? }\end{array}$ & Yes, no. \\
\hline
\end{tabular}

Based on the obtained results it is possible to in Russian and in foreign higher education draw up further recommendations on institutions aiming at creation of its own elimination of detected flaws in the area of methodology as well as for preparation of cross-cultural communication. Further developments may be used both by professors efficiency of the education. 


\begin{tabular}{|c|c|}
\hline Question & Options of answer \\
\hline $\begin{array}{l}\text { 1. Do you have friends from other foreign } \\
\text { countries? }\end{array}$ & Yes, no. \\
\hline 2. Have you ever travelled abroad? & Yes, no. \\
\hline $\begin{array}{l}\text { 3. Have you ever participated in any } \\
\text { international event that makes the } \\
\text { conversation with international students } \\
\text { possible? }\end{array}$ & Yes, no. \\
\hline $\begin{array}{l}\text { 4. Have you ever participated in the student } \\
\text { exchange program that enables to study a } \\
\text { language, living in the family abroad? }\end{array}$ & Yes, no. \\
\hline $\begin{array}{l}\text { 5. Could you say that preliminary intercultural } \\
\text { experience has positively influenced your } \\
\text { academic activity and cultural awareness? }\end{array}$ & Yes, no, difficult to answer. \\
\hline
\end{tabular}

\section{Statistical Analysis}

The analysis of the research data was performed in the system STATISTICA. The software was developed exclusively for analysis and visualisation of the data on the basis of Windows. Possible measurement error in survey data, while processing respondents' answers, might be no more than 7\%. Approximately 30 questionnaires were filled in, but not of an adequate quality (some respondents had failed to answer all questions of the questionnaire or chose more than one option of answer).

\section{Results}

In the first part of the research, the majority of full-time students (93\%) have stated that they can easily explain the concepts of communicative and cross-cultural competences. Moreover, $85 \%$ of the students are capable of differing these concepts that also testify for positive results of teaching foreign languages. These indices are very positive and demonstrate the overall positive tendency in terms of awareness of the specified issue. Therefore, the following outcomes show the positive dynamics: $86 \%$ of the students have pointed out the significance of cross-cultural competence in studying foreign languages. The same share of the students has agreed that intercultural knowledge is essential in achieving the necessary level of communication with foreigners. The students are aware of cross-cultural communication's importance in the context of studying a foreign language.

$60 \%$ of the respondents have stated that manuals of school and higher education institutions lack sufficient information about cultures of other countries. Whilst such information is necessary for the formation of cross-cultural competence, the conclusion is that the information stipulated in education manuals is poorly researched and cannot be used for achieving the proper level of cross-cultural competence.

However, it should be noted that over $80 \%$ of the students have stated that their education institution provides supplementary materials allowing them to acquire knowledge about culture of the countries of the studied languages. In this respect, the respondents were proposed to identify what specific materials have been provided by the institution. On Figure 1 the most frequently used options are presented. 


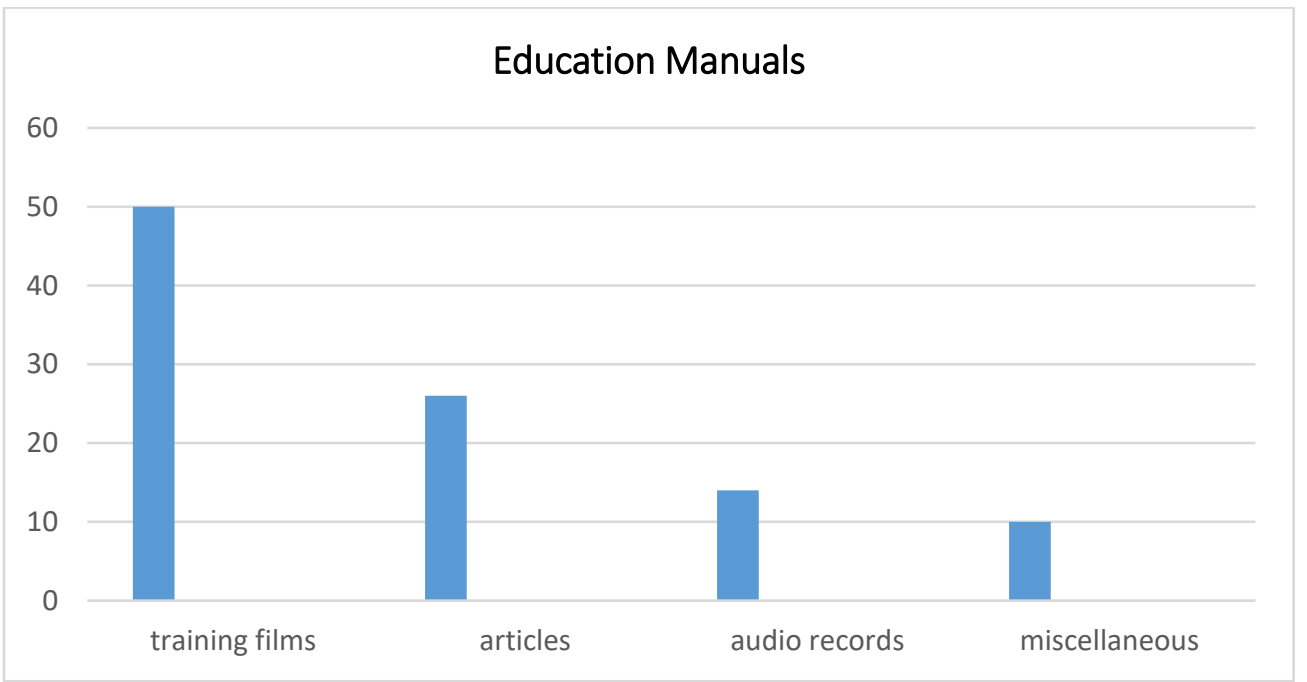

Figure 1: Supplementary Education Materials Aimed at Studying the Culture of other Countries

The majority of the students under the survey (91\%) have stated that the knowledge of crosscultural communication, obtained within the programme of education institution, is not sufficient and that real experience in crosscultural communication is needed. The students are not only aware of the importance of high cross-cultural competence as a whole but understand that for its development, there should be due conditions of real cross-cultural communication in place.

Only $37 \%$ of the students have pointed out that based on the online forums created in their universities it would be possible to cooperate, exchange information, and participate in discussions with other students, including the international ones.

Due to the outcomes of the first survey, it can be suggested that the students from specified higher education institutions are fully aware of the importance of cross-cultural communication for studying foreign languages as well as for making up a dialogue with representatives of other cultures. Therefore, it is acknowledged that the information received by the students is not sufficient for achieving the necessary level of cross-cultural competence because of the lack of real communication within other culture.

Based on the data of the second survey, the number of students who have at least one international student as a friend significantly exceeds the number of those who have no such friends ( $83 \%$ against 17\%). Ever since the extention of internet and promotion of cheaper and simple schemes of travelling have made intercultural contacts more popular.

In reference to the second question, the descriptive data have shown that trips to other countries are not popular among the students of higher education institutions of the Russian Federation. The ratio of those who were abroad compared to those who were not stands at: $53 \%$ and $47 \%$.

Almost half of the participants (47\%) have never been to other countries where they could take part in intercultural cooperation. It testifies that most Russian students do not participate directly in intercultural contacts. Such a situation can influence negatively the education of the students as it is deemed that practical intercultural experience is hugely important for strengthening cross-cultural competence of the students (Alred \& Byram, 2003).

The following question is aimed at the analysis of the intercultural experience of the students by assessing their participation in international events. According to the obtained data almost half of the students (52\%) have never participated in international events in their country or abroad. Such situation may be considered as unfavourable for acquiring intercultural awareness, improving knowledge and skills of the students. 
It is assumed that only $7 \%$ of students have ever taken part in exchange programmes. Thus, only a few Russian students have had relevant experience of immersion into another culture.

The above-mentioned analysis demonstrates that the Russian students studying at higher education institutions do not often have intercultural contacts during the education time. Nevertheless, $83 \%$ of the students have foreign friends, $53 \%$ have travelled abroad, and $48 \%$ have attended intercultural events. The conclusion is that higher education institutions need to extend the system of academic flexibility programmes allowing the students to go abroad and gain direct intercultural experience.

The cross-cultural competence should incorporate concise goals and approaches if higher education institutions tend their activities towards the preparation of their graduates for obtaining education in the conditions of globalisation (Block \& Cameron, 2002).

Summing up those above, the issue stipulated in research is considered in many aspects. It is supposed that the content of educational programmes does not fully cover the necessary level of development of cross-cultural competence among students as well as sufficient experience of real cross-cultural communication, which is necessary for studying a language within new social and cultural environment. The issue still requires a systematic approach.

\section{Strategies and Methods of Developing Cross- Cultural Competence among Students}

The development strategy should be clearly planned both by professors and students. First of all, students themselves have to be aware of the reason why cross-cultural competence is so necessary, what is a practical value of obtained information. Moreover, the students should definitely understand how they can make use of received knowledge for their career development.

\section{The Key Role of a Professor}

A professor in the educational process might influence positively the formation of cross- cultural and due language competences. One of the methods of raising specified competences is discussion that can be applied for lectures and, besides, requires a high level of knowing the studied language. For certain lectures, professor can prepare the theme which incorporates any cultural information that students are proposed to discuss. In this case there will be not only extension of background knowledge about certain culture but also the improvement in studying a language, communicative competence, development of the skill to participate in discussions and critical thinking.

\section{Additional Information Sources}

Based on research results, the students of the Russian higher education institutions think that education manuals do not provide adequate information that is necessary for the development of cross-cultural competence. Moreover, the survey has shown that the majority of students still receive supplementary materials which help to get sufficient information which may be considered as a definite practical skill.

\section{Online Forums for Communication with Foreign Students}

Online forums are effective and convenient online education tools allowing students to exchange cultural information and increase their level of acquiring a foreign language. Creation and maintenance of such a platform are entirely under responsibility of the administration of the university as the process requires certain tangible expenses. In addition, for its creation those professors and methodologists should be engaged, who can provide definite useful recommendations. Discussion forums allow students to develop their languages capabilities and exchange cultural experience.

\section{The Organisation of Participation in International Events and Exchange Programmes}

One of the effective ways of increasing the level of cross-cultural competence within the native country can be considered participation in international events. Such events allow students not only to increase the level of language 
knowledge and cooperate with representatives of other cultures but also to learn how to collaborate with them on a business level. In this regard, the university's administration should ensure the participation of students in international events and as far as possible to hold such events within the educational institution.

\section{Discussion}

One of the key aims of the research was to examine the issues and strategies of formation of language competence in cross-cultural communication. Similar research was carried out in Turkey at Kadir Has University (Aba, 2016; 2017). Unlike the present research, the survey at Kadir Has University was conducted among students of the first-fourth years of study. The research was aimed at clarifying whether the level of cross-cultural competence depends on the age and the year of education.

Data were collected with the help of a combined questionnaire form. The form consisted of two parts. For calculations of results Pearson's chisquared test was selected in the programme SPSS. Hence, as in contrary to Russian students, the large ratio of Turkish students have at least one foreign friend but lower ratio of those who can travel abroad. It is worth to point out that the data concerning students of different education years do not crucially differ. It can be concluded that intercultural experience does not depend on the student's age.

For the second part of the survey, the questions related to the motivation of the students in regards to academic flexibility were covered. At the beginning the students were asked to define whether they wish to join the program of academic exchange such as Erasmus with the purpose of going abroad for further education. It was supposed that the students who have had many intercultural contacts were far more eager to travel abroad with the purpose to continue the study. In addition, the survey was also conducted to identify the relationship between the motivation in terms of academic flexibility and intercultural experience.
Both surveys demonstrated the existence of the significant relationship between the motivation for academic flexibility and presence of foreign friends. Otherwise stated, the presence of foreign friends had a positive impact on the readiness of the students to continue the study in a new culture and country. Travelling abroad, however, did not show a critical relationship with the motivation for academic flexibility. Therefore, it can be summarised that the existence of personal relationships impacts the desire to acquire intercultural experience. This observation is similar to the findings made by Field (2013).

As students of the majority of the countries do not acquire intercultural experience directly in their academic life, the education institutions should pay special attention to the extension of intercultural contacts, which have a strong positive impact on cross-cultural competence (Roy, 2006). According to the above-mentioned results, the cross-cultural competence should not be taken for granted, as long as it is an acquired factor, which indeed needs to be developed and improved (Deardorff, 2006; 2010).

\section{Conclusion}

The surveys have demonstrated that most of the students understand and use the concepts "language competence" and "cross-cultural competence". They also perceive the importance of international communication. In the framework of the research, it was also found out that it is rather challenging to obtain a sufficient cross-cultural competence within one educational institution. As in this case, students cannot be directly engaged in cross-cultural communication.

In order to solve the above-mentioned issues, it is necessary to provide students with supplementary training materials and programmes aimed at acquiring knowledge about countries of the studied languages. The university's administration should pay due attention to the organisation of the relevant online environment for students where they communicate with international students as well as revise the materials. The latter will allow 
improving cross-cultural competence and the level of the studied language. Participation in various international exchange programmes and international educational events enables students to immerse fully into another culture.

Best practices and outcomes of the present article may, in future be of great help for Russian universities and also for other countries with the purpose of studying cross-cultural competence within establishing international dialogue. This research can be valuable for the activities of professors and scientists of those faculties where cross-cultural communication plays a crucial role, for example, faculties of international affairs.

\section{References}

Aba, D. (2015). Towards a cross-cultural communication competence tool for academic mobility purposes. Journal of Cross-cultural communication, 39(6), 6.

Aba, D. (2016). Addressing intercultural experience and academic mobility in higher education. Journal of Cross-cultural communication Research, 45(6), 487-502. doi: 10.1080/17475759.2016.1236032

Akizhanova, D. M., Zharkynbekova, S. K., \& Satenova, S. K. (2018). The Zipf's law and other ways of identifying culture-specific linguistics units. Space and Culture, India, 6(2), 78-93. doi: 10.20896/saci.v6i2.363

Alred, G., \& Byram, M. (2003). Intercultural experience and education. Multilingual matters Ltd.Clevedon.

Baraldi, C. (2006). New forms of cross-cultural communication in a globalised world. International Communication Gazette, 68(1), 53-69. doi: $10.1177 / 1748048506060115$

Barker, G. G. (2016). Cross-cultural perspectives on cross-cultural communication competence. Journal of Cross-cultural communication Research, 45(1), 13-30. doi: $10.1080 / 17475759.2015 .1104376$

Barrett, M. (2013). Intercultural competence: A distinctive hallmark of interculturalism. Interculturalism and multiculturalism:
Similarities and differences (pp. 147-168). Strasbourg: Council of Europe Publishing. Block, D., \& Cameron, D. (Eds.). (2002). Globalisation and language teaching. London and New York: Routledge.

Cameron, D. (2002). Globalisation and the teaching of 'communication skills'. In Globalisation and language teaching (pp. 77-92). London: Routledge.

Celce-Murcia, M. (2008). Rethinking the role of communicative competence in language teaching. In Intercultural language use and language learning (pp. 41-57). Springer, Dordrecht. doi: 10.1007/978-14020-5639-0_3

Chamot, A. U. (2004). Issues in language learning strategy research and teaching. Electronic Journal of foreign language teaching, 1(1), 14-26.

Chen, G. M. (2011). An introduction to key concepts in understanding the Chinese: Harmony as the foundation of Chinese communication. China Media Research, $7(4), 1-12$.

Deardorff, D. K. (2006). Identification and assessment of intercultural competence as a student outcome of internationalisation. Journal of studies in international education, 10(3), 241-266. doi: $10.1177 / 1028315306287002$

Deardorff, D.K. (2010). Intercultural competence in higher education and intercultural dialogue. In Speaking across borders: The role of higher education in furthering intercultural dialogue (pp. 87100). Strasbourg: Council of Europe.

Fahrutdinova, R. A., Yarmakeev, I. E., \& Fakhrutdinov, R. R. (2014). The Formation of Students' Foreign Language Communicative Competence during the Learning Process of the English Language through Interactive Learning Technologies (The Study on the Basis of Kazan Federal University). English Language Teaching, 7(12), 36-46.

Field, A. (2013). Discovering statistics using IBM SPSS statistics (pp. 952). Los Angeles, CA: Sage 
Gudykunst, W. B., Lee, C. M., Nishida, T., \& Ogawa, N. (2005). Theorizing about intercultural communication. Theorizing about intercultural communication (pp. 332). Thousand Oaks, CA: Sage Publications.

Kiynova, Z. K. K., Sansyzbayeva, S. K., Akhmetzhanova, A. I., Mussabekova, U. E., \& Muratbayeva, I. S. (2018). Kazakhstan realities in the perception of representatives of American ethnolinguoculture. Space and Culture, India, 6(3), 71-81. doi: 10.20896/saci.v6i3.370

Koester, J., \& Lustig, M. (2012). Intercultural competence: Interpersonal communication across cultures. Pearson Prentice Hall.

Lantz-Deaton, C. (2017). Internationalisation and the development of students' intercultural competence. Teaching in Higher Education, 22(5), 532-550. doi: 10.1080/13562517.2016.1273209

Lee, C. K. (2010). An overview of language learning strategies. Annual Review of Education, Communication \& Language Sciences, 7, 132-152.

Mukhtarova, S. S., Karagulova, B., Sideshova, Z., Mukhtarov, S., Yergazina, A., \& Nasipov, I. (2019). Translating the untranslatable: challenges, sticking points and struggles. Space and Culture, India, 7(1), 250-263. doi: 10.20896/saci.v7i1.421

Novikova, O., Muryasov, R., Aznabaeva, A., Belyaev, A., Kalugina, Y., Mustafina, A., ... \& Khazhieva, Z. (2019). Ethno-lingual distribution of anthroponyms in the name system of multinational region. Space and Culture, India, 7(1), 104-116. doi: 10.20896/saci.v7i1.418

Oliver, R., Haig, Y., \& Rochecouste, J. (2005). Communicative competence in oral language assessment. Language and education, 19(3), 212-222. doi: $10.1080 / 09500780508668675$
Piller, I. (2017). Cross-cultural communication: A critical introduction. Edinburgh University Press: Edinburgh

Roy, L. (2006). In search of the global graduate: Transforming international experience into intercultural competence. Doctoral dissertation, Concordia University. Retrieved from https://spectrum.library.concordia.ca/912 8/

Safina, M. S. (2014). Formation of socio-cultural competence in foreign language teaching. Procedia-Social and Behavioral Sciences, 136, 80-83. doi: 10.1016/j.sbspro.2014.05.292

Sam, D. L., \& Berry, J. W. (2010). Acculturation: When individuals and groups of different cultural backgrounds meet. Perspectives on Psychological Science, 5(4), 472-481. doi: $10.1177 / 1745691610373075$

Savignon, S. J. (2017). Communicative Competence. New Haven, CT: Yale University Press.

Spencer-Rodgers, J., \& McGovern, T. (2002). Attitudes toward the culturally different: The role of cross-cultural communication barriers, affective responses, consensual stereotypes, and perceived threat. International Journal of Intercultural Relations, 26(6), 609-631. doi: 10.1016/S0147-1767(02)00038-X

Tsapko, M. I., Valyarovskiy, F. I., Maiboroda, E. T., Khusainova, E. N., \& Varnavskaya, O. O. (2018). Language identity as a unifying identity: Linguistic, ethnopolitical and international legal aspects. Space and Culture, India, 6(2), 121-129. doi: 10.20896/saci.v6i2.360

Xu, K. (2013). Theorizing difference in crosscultural communication: A critical dialogic perspective. Communication Monographs, 80(3), 379-397. doi: 10.1080/03637751.2013.788250 